\title{
A comparison of cylindrical and Inoue balloon techniques for mitral valvotomy in patients in the United Kingdom
}

\author{
T R D Shaw, C M Turnbull, P Currie, A D Flapan, S Pringle, B C Lee
}

\begin{abstract}
Objectives-To compare the use of cylindrical balloons and the Inoue balloon for percutaneous mitral valvotomy in patients in the United Kingdom.

Design-Comparison of the haemodynamic results, complications, and symptomatic outcome of ballon dilatation for mitral stenosis in consecutive patients treated by cylindrical balloons and a second consecutive series of patients treated by the Inoue balloon.
\end{abstract}

Setting-A tertiary cardiac referral centre in Scotland.

Patients-70 patients (mean age 60.6 years) treated by the single or double cylindrical balloon technique and 70 patients (mean age 58.9 years) treated with the Inoue balloon method.

Main outcome measures-Success in obtaining dilatation at the mitral orifice, procedure and screening times, increase in valve area, complications, and early symptomatic outcome.

Results-Dilatation of the mitral valve was obtained in $91 \%$ of patients when cylindrical balloons were used and in $99 \%$ of patients treated with the Inoue balloon. Use of the Inoue balloon gave significantly shorter procedure and screening times. Technical problems in obtaining and maintaining the position at the mitral orifice were more common with cylindrical balloons. Improvements in valve area and symptoms were not significantly different with use of the two types of balloon. The Inoue balloon avoided cardiac tamponade and the creation of larger atrial septal defects, but had a higher incidence of increase in mitral reflux.

Conclusions-In these elderly patients, the Inoue balloon method was safer and faster for percutaneous mitral valvotomy, with a higher success rate for dilatation within the valve orifice. Haemodynamic and symptomatic improvement was similar with the two techniques.

(Br Heart f 1994;72:486-491)
Several techniques have been described for performing percutaneous mitral balloon valvotomy. Lock et al ${ }^{1}$ used a single cylindrical balloon which reached the mitral valve, via atrial septal puncture, over a guide wire which had been advanced to the aorta. The double cylindrical balloon technique of Al Zaibag et $a l^{2}$ provided a larger dilatation and better haemodynamic results. Catheters with a single shaft and two ("Bifoil") or three ("Trefoil") cylindrical balloons attached have been produced. ${ }^{3}$ Retrograde approach of the balloon to the mitral orifice, with and without transseptal puncture, has also been described. ${ }^{45}$ These were all "over the wire" techniques using non-compliant balloons and were successful in improving the severity of mitral stenosis. ${ }^{6-9}$ In 1989 the commercial availability of the Inoue balloon introduced a significantly different approach for mitral balloon valvotomy. ${ }^{1011}$ The Inoue balloon had compliance characteristics designed to assist positioning and stability at the mitral orifice and to allow a series of dilatations over a range of sizes (figure). It was provided with a dilator and a double coil guide wire. The Inoue balloon was directed towards the mitral orifice by a curved stylet rather than over a guide wire.

We have compared our experience of using cylindrical balloons for mitral valvotomy in 70 patients with the use of the Inoue balloon for a further 70 patients. Most of the patients in this series were elderly, reflecting the more advanced age at which severe mitral stenosis now presents in the United Kingdom.

\section{Patients and methods}

PATIENTS

Up to September 1989, mitral valve dilatation using cylindrical balloons was attempted in 70 consecutive patients and thereafter the Inoue balloon was used in a further consecutive 70 patients. Table 1 gives the characteristics of these two groups of patients. The mean age of the 140 patients was 59.8 years. Patient characteristics in the two groups were similar, but more patients treated by cylindrical balloons had moderately or heavily calcified valves. Patients had been referred from cardiac 


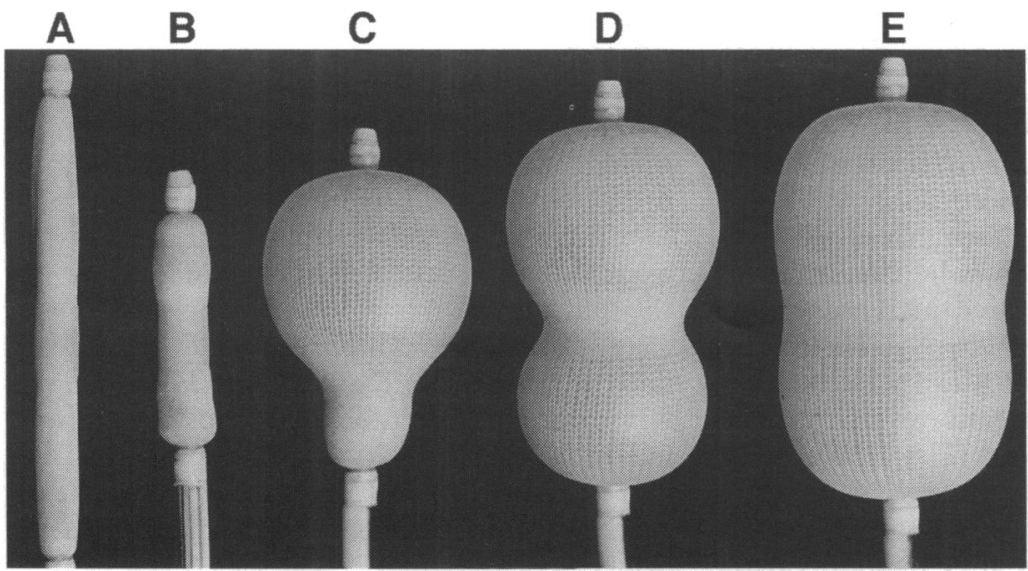

The Inoue balloon. (A) The balloon has been stretched by inserting the 18 gauge metal tube to slenderise the profile for insertion through the skin and atrial septum. (B) The undilated balloon after removal of the metal tube. (C) Inflation occurs first in the distal portion and the balloon can be drawn back against the valve orifice. (D) Further injection inflates the proximal portion, tending to hold the balloon at the valve orifice. (E) Finally, the middle portion is inflated, to an extent controlled by the total volume of injection.
The number of dilatation sizes used up to and including the final size was: 1,10 patients; 2, 35 patients; 3, 17 patients; 4, six patients; and 5, two patients.

The mean cross sectional dilated balloon area normalised for body surface area $^{12}$ was $3 \cdot 15 \mathrm{~cm}^{2} / \mathrm{m}^{2}$ using the cylindrical balloons and $3.82 \mathrm{~cm}^{2} / \mathrm{m}^{2}$ for the Inoue balloon.

Patients had received warfarin before balloon valvotomy unless there was a contraindication to anticoagulation. Intravenous heparin, 100 units/kg body weight, was given after transseptal puncture.

Cardiac output was measured with the Fick principle using assumed oxygen uptake. ${ }^{12}$ The mean mitral valve gradient was measured by planimetry. Valve area was calculated by the Gorlin equation. ${ }^{12-14}$ After withdrawal of the balloon catheter, the cardiac output and any left to right shunt was calculated from right heart oxygen saturations. All patients had echocardiograms on the morning before and after valvotomy.

departments throughout Scotland: $97 \%$ of the patients had been born in the United Kingdom.

\section{METHODS}

The technique for valvotomy using cylindrical balloons was based on that described by Lock et al. ${ }^{1}$ The double balloon technique ${ }^{2}$ was attempted if a single $25 \mathrm{~mm}$ balloon gave an inadequate result. A single $25 \mathrm{~mm}$ balloon (Mansfield Scientific Co.) was used in 31 patients and a $30 \mathrm{~mm}$ balloon in one patient. The double balloon technique was used in 22 patients with balloon sizes from $15+15 \mathrm{~mm}$ to $15+25 \mathrm{~mm}$. A Trefoil balloon catheter with $3 \times 12 \mathrm{~mm}$ or $3 \times 15 \mathrm{~mm}$ balloons (Schneider-Shiley) was used in 10 patients. In six patients the balloon was not dilated due to a failure to achieve position at the mitral orifice.

The Inoue balloon was used in the manner described by Inoue. ${ }^{1011}$ In one patient the balloon could not be made to cross the mitral orifice. Final dilatation size was: $24 \mathrm{~mm}, 3$; $25 \mathrm{~mm}, 4 ; 26 \mathrm{~mm}, 8 ; 27 \mathrm{~mm}, 11 ; 28 \mathrm{~mm}$, 13; $29 \mathrm{~mm}, 3$; $30 \mathrm{~mm}, 22$; and $32 \mathrm{~mm}, 6$.

\section{Results}

ACHIEVING DILATATION AT THE MITRAL ORIFICE

Of the 70 patients undergoing valvotomy with cylindrical balloons, dilatation at the mitral valve was achieved in $64(91 \%)$. In one patient the atrial septum could not be crossed, in two the guide wire could not be negotiated through the mitral orifice, and in three patients the guide wire was advanced to the left ventricle or aorta but the balloon could not be made to follow across the mitral orifice.

With the Inoue balloon, dilatation at the orifice was achieved in 69 of 70 patients $(99 \%)$. In one patient with severe stenosis, the Inoue balloon could not be negotiated through the mitral valve.

\section{HAEMODYNAMIC AND SYMPTOMATIC} IMPROVEMENT

Table 1 gives the characteristics of the patients in whom dilatation of the mitral orifice was achieved. One patient in the cylindrical balloon group died before postdilatation

\begin{tabular}{|c|c|c|c|c|c|c|c|c|c|c|c|c|c|c|c|c|}
\hline \multirow{3}{*}{$\begin{array}{l}\text { Type of } \\
\text { balloon } \\
\text { used }\end{array}$} & \multirow{3}{*}{$\begin{array}{l}\text { No (\%) } \\
\text { female } \\
\text { patients }\end{array}$} & \multirow{3}{*}{$\begin{array}{l}\text { Mean } \\
\text { (SD) } \\
\text { (range) } \\
\text { age } \\
\text { (years) }\end{array}$} & \multirow{2}{*}{\multicolumn{4}{|c|}{$\begin{array}{l}\text { No (\%) in each } \\
\text { NYHA } \\
\text { Symptom class }\end{array}$}} & \multirow{3}{*}{$\begin{array}{l}\text { No (\%) } \\
\text { with } \\
\text { previous } \\
\text { surgical } \\
\text { Valvotomy }\end{array}$} & \multirow{3}{*}{$\begin{array}{l}\text { No (\%) } \\
\text { with } \\
\text { atrial } \\
\text { fibrillation } \\
\text { present }\end{array}$} & \multirow{3}{*}{$\begin{array}{l}\text { No (\%) } \\
\text { with left } \\
\text { ventricular } \\
\text { impairment }\end{array}$} & \multirow{3}{*}{$\begin{array}{l}\text { No (\%) } \\
\text { with } \\
\text { coronary } \\
\text { artery } \\
\text { disease }\end{array}$} & \multirow{3}{*}{$\begin{array}{l}\text { No (\%) } \\
\text { receiving } \\
\text { warfarin }\end{array}$} & \multirow{3}{*}{$\begin{array}{l}\text { Mean } \\
\text { (SD) } \\
\text { frusemide } \\
\text { dose } \\
\text { (mg) }\end{array}$} & \multicolumn{2}{|c|}{$\begin{array}{l}\text { No (\%) } \\
\text { with } \\
\text { valve } \\
\text { calcification }\end{array}$} & \multirow{3}{*}{$\begin{array}{l}\text { Mean } \\
\text { (SD) } \\
\text { echocardio- } \\
\text { graphic } \\
\text { score }\end{array}$} & \multirow{3}{*}{$\begin{array}{l}\text { No (\%) } \\
\text { with } \\
\text { echo- } \\
\text { cardio- } \\
\text { graphic } \\
\text { score } \\
>8\end{array}$} \\
\hline & & & & & & & & & & & & & \multirow{2}{*}{$\begin{array}{l}\text { None } \\
\text { or } \\
\text { mild }\end{array}$} & \multirow{2}{*}{$\begin{array}{l}\text { Moderate } \\
\text { or } \\
\text { severe }\end{array}$} & & \\
\hline & & & $I$ & II & III & $I V$ & & & & & & & & & & \\
\hline \multicolumn{17}{|c|}{ A: Patients in whom balloon dilatation attempted } \\
\hline $\begin{array}{l}\text { Cylindrical } \\
(\mathrm{n}=70)\end{array}$ & $53(76)$ & $\begin{array}{l}60 \cdot 6(12 \cdot 2) \\
(31-82)\end{array}$ & $0(0)$ & $13(19)$ & $33(47)$ & $24(34)$ & $21(30)$ & $48(69)$ & $14(20)$ & $15(21)$ & $60(86)$ & $104(86)$ & - & - & - & - \\
\hline $\begin{array}{l}\text { Inoue } \\
\quad(n=70)\end{array}$ & $55(79)$ & $\begin{array}{l}58 \cdot 9(12 \cdot 8) \\
(12-82)\end{array}$ & $0(0)$ & $17(24)$ & $38(54)$ & $15(21)$ & $17(24)$ & $53(76)$ & $9(13)$ & $20(29)$ & $63(90)$ & $78(74)$ & - & - & - & - \\
\hline \multicolumn{17}{|c|}{ B: Patients in whom balloon dilatation achieved } \\
\hline $\begin{array}{r}\text { Cylindrical } \\
(\mathrm{n}=63)\end{array}$ & $46(73)$ & $\begin{array}{l}60 \cdot 1(12 \cdot 3) \\
(31-82)\end{array}$ & $0(0)$ & $13(19)$ & $30(48)$ & $20(32)$ & $19(30)$ & $42(67)$ & $13(21)$ & $13(21)$ & $55(87)$ & $98(81)$ & $31(49)$ & $32(51)^{*}$ & $7 \cdot 7(3 \cdot 3)$ & $27(43)^{\star \star}$ \\
\hline $\begin{array}{l}\text { Inoue } \\
(n=69)\end{array}$ & $54(78)$ & $\begin{array}{l}58 \cdot 9(12 \cdot 9) \\
(12-82)\end{array}$ & $0(0)$ & $17(25)$ & $37(54)$ & $15(22)$ & $16(23)$ & $53(77)$ & $9(13)$ & $20(29)$ & $63(91)$ & $77(75)$ & $50(72)$ & $19(29)$ & $6.4(2.9)$ & $12(17)$ \\
\hline
\end{tabular}


measurements could be made and is not included in table 1 . Table 2 gives the changes in haemodynamic indices before dilatation and after the last dilatation. For the two types of balloon, these changes were statistically significant $(P<0.001$, paired test). With the cylindrical balloons, valve area increased from 0.87 to $1.55 \mathrm{~cm}^{2}(+78 \%)$, whereas with the Inoue balloon the valve area increased from 0.89 to $1.77 \mathrm{~cm}^{2}(+99 \%)$. The mean increase in valve area with the Inoue balloon was not statistically different to that found with the cylindrical balloons $(P=0 \cdot 06)$.

Table 2 also gives the mean New York Heart Association symptom class score before and one to three months after balloon valvotomy for the two treatment groups. In many of these elderly patients the symptomatic improvement was limited by associated disease. In others a suboptimum haemodynamic result was related to marked degenerative changes at the mitral valve. With the cylindrical balloons, the symptom score improved by a mean (SD) of $0.98(0.73)$ and with the Inoue balloon the mean (SD) improvement was $1.20(0.72)$; the difference between the groups was not statistically significant $(P=$ 0.09 , unpaired $t$ test).

\section{SCREENING/PROCEDURE TIMES}

The mean (SD) fluoroscopy screening time for patients dilated using the cylindrical balloons was $40 \cdot 1(17 \cdot 6)$ minutes and with the Inoue balloon $24.3 \quad(9.3)$ minutes $(\mathrm{P}<$ $0 \cdot 001)$. Total procedure time, which usually included a full initial diagnostic study with coronary angiography, was $2.02(0.69)$ hours with cylindrical balloons and $1.35(0.39)$ hours with the Inoue balloon $(P<0.001)$.

\section{TECHNICAL DIFFICULTIES}

Several technical problems were encountered with the cylindrical balloons.

(a) The catheter shafts were relatively stiff and difficult to advance around and forward from an enlarged left atrial cavity into the mitral orifice.

(b) On dilatation, their shape did not resist any tendency to backward or forward ejection from a resistant mitral orifice.

(c) Cylindrical balloons did not regain their low profile shape after inflation. If ejected back into the left atrium, the wrinkled leaf shape taken on after dilatation could make recrossing of the mitral orifice impossible unless the balloon was withdrawn and rewrapped in vitro.

Table 2 Haemodynamic and symptomatic changes before and after balloon dilatation with cylindrical and Inoue balloons. Values are mean (SD)

\begin{tabular}{|c|c|c|c|c|}
\hline & \multicolumn{2}{|c|}{ Cylindrical balloons $(n=63)$} & \multicolumn{2}{|c|}{ Inoue balloon $(n=69)$} \\
\hline & Before & After & Before & After \\
\hline $\begin{array}{l}\text { Mitral valve gradient }(\mathrm{mm} \mathrm{Hg}) \\
\text { Cardiac output }(1 / \mathrm{min}) \\
\text { Valve area }\left(\mathrm{cm}^{2}\right) \\
\text { Mean left atrial }(\mathrm{mm} \mathrm{Hg}) \\
\text { Mean NYHA symptom score at } \\
\text { 1-3 months after valvotomy. }\end{array}$ & $\begin{array}{c}14 \cdot 3(5 \cdot 2) \\
3 \cdot 68(1 \cdot 04) \\
0 \cdot 87(0 \cdot 29) \\
22 \cdot 2(6 \cdot 2) \\
3 \cdot 1(0 \cdot 7)\end{array}$ & $\begin{array}{c}6 \cdot 6(2 \cdot 6) \\
4 \cdot 34(1.19) \\
1.55(0.47) \\
14 \cdot 6(5 \cdot 2) \\
2 \cdot 2(0 \cdot 9)\end{array}$ & $\begin{array}{c}13.8(5 \cdot 2) \\
3.80(1.11) \\
0.89(0.31) \\
26.7(6.6) \\
3.0(0.7)\end{array}$ & $\begin{array}{c}6 \cdot 1(3.2) \\
4.60(1.81) \\
1.77(0.91) \\
21.7(7 \cdot 0) \\
1.8(0.9)\end{array}$ \\
\hline
\end{tabular}

NYHA = New York Heart Association (d) A $30 \mathrm{~mm}$ balloon was too stiff for effective use.

(e) If a $25 \mathrm{~mm}$ balloon gave inadequate bilateral commissure splitting then a double balloon technique was necessary, which increased the complexity and difficulty of balloon placement within the mitral orifice-for example, the second balloon could snag on the first balloon.

(f) When the cylindrical balloon catheter had a pigtail end, this tended to make advancement over the guide wire into the orifice more difficult - in some patients, the pigtail end had to be cut from the catheter before it would advance through the mitral orifice.

(g) With the Trefoil format, a kink in the proximal end of a balloon could prevent deflation until the kink was released-for example, by pulling back into the atrial septum.

The following technical problems were found with the Inoue balloon.

(a) Although the special compliance characteristics of the Inoue balloon made it effective in preventing backward ejection of the balloon on the first inflation, backward ejection to the left atrium could occur after the valve orifice was widened by initial dilatation. This was usually able to be prevented by avoiding an excessive backward pull on the catheter when the balloon was placed at the orifice.

(b) In some patients with marked subvalvular change, the Inoue balloon displaced forward into the left ventricular cavity. It did not reach as far as the apex, however. This displacement could be prevented by firmer backward pressure on the catheter after dilatation of the distal portion of the balloon.

(c) In two patients; the stiff Inoue stylet wire caused displacement of Inoue balloon back into the right atrium when the stylet was being reinserted after left atrial pressure measurement after initial inflation. It was found that the Inoue balloon should be advanced well into the left atrium before the stylet wire was reintroduced so that upward pressure on the curve within the right atrium did not produce this displacement.

(d) The Inoue balloon's blunter tip usually made percutaneous entry to the femoral vein more difficult. Firm pressure was often needed to achieve entry into the vein: occasionally, a peel away sheath had to be used.

\section{COMPLICATIONS}

Table 3 gives the complications seen in the 64 patients in whom dilatation with cylindrical balloons was achieved and in the 69 patients who had dilatation with the Inoue balloon.

\section{Rhythm changes}

Ventricular ectopic beats and short runs of ventricular tachycardia were more common with the cylindrical balloon technique because of the presence and manipulation of the guide wires within the left ventricle. This was well tolerated by all but one patient with 
Table 3 Complications found with cylindrical and Inoue balloons at mitral balloon valvotomy. $M V R=$ mitral valve replacement. Statistical significance is by $\chi^{2}$ test. Values are No (\%) patients.

\begin{tabular}{|c|c|c|c|}
\hline & $\begin{array}{l}\text { Cylindri } \\
(n=63\end{array}$ & lloons & $\begin{array}{l}\text { Inoue balloon } \\
(n=69)\end{array}$ \\
\hline Atrial septal defect $\geqslant 1 \cdot 2: 1$ & $8(11)$ & \multirow{2}{*}{$P<0.1$} & $3(4)$ \\
\hline $\begin{array}{l}\text { Embolism } \\
\text { Haemopericardium } \\
\text { Increase in mitral reflux by } \geqslant 1 \text { grade }\end{array}$ & $\begin{array}{l}2(3) \\
3(5) \\
2(3)\end{array}$ & & $\begin{array}{c}1(1) \\
0(0) \\
16(23)\end{array}$ \\
\hline $\begin{array}{l}\text { Mitral reflux requiring early MVR } \\
\text { Myocardial impairment not due to overt }\end{array}$ & $0(0)$ & $P<0.01$ & $3(4)$ \\
\hline $\begin{array}{l}\text { coronary embolism } \\
\text { In-hospital mortality }\end{array}$ & $\begin{array}{l}0(0) \\
3(4 \cdot 7)\end{array}$ & & $\begin{array}{l}2(3) \\
1(1)\end{array}$ \\
\hline
\end{tabular}

bifasicular conduction disease, however, who developed transient asystole after a run of ventricular tachycardia induced by guide wire manipulation. One patient in the Inoue group also developed transient asystole: this appeared to be due to balloon dilatation being repeated too soon after a first inflation had been carried out at a suboptimum position. One patient in each group converted from sinus rhythm to atrial flutter/fibrillation during balloon valvotomy.

\section{Atrial septal defect}

A left to right shunt of $1 \cdot 2: 1$ or more at the atrial septal crossing point was detected in eight $(11 \%)$ of the cylindrical balloon patients and in three $(4 \%)$ of the patients treated by the Inoue balloon $(P<0.01)$. The mean severity of shunting was $1 \cdot 50: 1$ and $1 \cdot 27: 1$ respectively for the two balloon types. Two of the patients in the cylindrical balloon group developed evidence of increasing right heart dilation and required surgical closure of the atrial defect.

\section{Embolism}

Two patients, treated by cylindrical balloons, developed embolism after the procedure. One, critically ill with systemic lupus erythematosus vasculitis, chronic obstructive airways disease, left ventricular impairment, and a past history of stroke, had become agitated during the procedure and required sedation, which caused hypoxia and hypotension. He required assisted ventilation after balloon valvotomy and showed evidence of hemiplegia two days later. The second patient, who had developed a small self limiting haemopericardium, went into atrial fibrillation the day after balloon valvotomy. Anticoagulants had been discontinued because of the haemopericardium. She developed an embolus to the leg six hours after valvotomy; with heparin treatment her foot pulses returned to normal. She restarted warfarin treatment but had a transient hemiplegia three weeks after valvotomy.

In the Inoue group, one patient developed an embolus to the anterior descending coronary artery immediately after the first valve dilatation. Coronary balloon angioplasty was unsuccessful at compressing the small embolus but displaced it more distally. The patient sustained a moderately sized anterior infarct.

\section{Haemopericardium}

Three patients treated with the cylindrical type of balloon developed haemopericardium (5\%). In two patients cardiac tamponade was found due to perforation at the left ventricular apex. One patient died and one patient survived after closure of the myocardial tear at emergency thoracotomy. In the third patient, a small collection of fluid in the pericardium developed one hour after the procedure, but was self limiting and did not require aspiration. No patient treated by the Inoue balloon developed haemopericardium.

\section{Mitral reflux}

Increase in mitral reflux after dilatation was more common with use of the Inoue balloon. An increase in mitral reflux by at least one grade was found after dilation in two patients (3\%) of the cylindrical balloon group and in $16(23 \%)$ of the Inoue group. In three of the patients treated by the Inoue balloon, there was a marked increase in mitral reflux which required early but not emergency mitral valve replacement.

\section{Myocardial impairment}

In addition to the patient with coronary embolism, two other patients, both in the Inoue group, developed evidence of localised myocardial impairment after valve dilation: both had severe coronary artery disease. One developed inferior surface akinesia without chest pain, whereas the second developed pain, ST elevation, and anterior wall akinesia. The patient with anterior infarction died three days later and at necropsy no evidence of thrombotic or commissural fragment embolism was found.

\section{Death}

Three patients $(5 \%)$ in the cylindrical balloon group died before leaving hospital. The patient with systemic lupus erythematosus vasculitis who had a stroke after valvotomy died two weeks later. A second patient, with severe mitral stenosis and severe obstructive airways disease, had marked orthopnoea and required a general anaesthetic for the balloon valvotomy; she died of respiratory failure four hours after her balloon valvotomy. The third patient died after developing haemopericardium. One patient ( $1 \%$ ) treated by the Inoue balloon died after anterior infarction.

\section{Discussion}

Many of the patients in our series were elderly: the mean age was $59 \cdot 8$ years. Often percutaneous balloon valvotomy was undertaken because they had an absolute or strong contraindication to surgical treatment. ${ }^{15-17}$ Their older age reflects the decreased severity of acute rheumatic fever in the United Kingdom $^{12}$ and also restenosis in patients who had a previous successful surgical valvotomy (27\% of our patients). With these older patients, cardiomegaly is more marked, associated coronary disease and myocardial 
impairment are more common, and the mitral valve has more degenerative changes.

In this patient population, several important differences between the balloon techniques were apparent. The Inoue balloon had a higher success rate for crossing the stenosed mitral orifice. It was also a faster procedure with a reduced fluoroscopy screening time despite the fact that it is designed to allow a series of dilatations of increasing size rather than a single dilatation. The Inoue balloon gave a shorter procedure time because it avoided some of the technical difficulties experienced with the cylindrical balloonsparticularly the problems of advancing the relatively stiff cylindrical balloons around an enlarged left atrium, the ejection of straight walled balloons from resistant mitral orifices, and the need to remove and rewrap the balloons before they could be made to recross the mitral orfice. Although technical problems lessen with operator experience, the number of patients in each of our treatment groups was the same, giving an equivalent learning curve.

We found that the two techniques produced a similar haemodynamic and symptomatic outcome. Our study was not randomised, however, and cannot offer a precise comparison of haemodynamic result. Although the patients in the two groups had similar clinical characteristics marked mitral degenerative change was common in the earlier group in which a range of cylindrical balloon size was used. In another nonrandomised comparison of 73 patients treated with an Inoue balloon and 21 treated by the double balloon technique Chen et al ${ }^{18}$ found that in their young patients (mean age 33.8 ) the two balloons gave similar results, but the Inoue balloon achieved a significantly lower postdilatation gradient. Abdullah et al ${ }^{19}$ used the double balloon technique for 60 consecutive patients and then the Inoue balloon for a further 60 patients: their mean age was 33.5 years. They also found that haemodynamic and symptomatic improvement was similar with use of the two types of balloon, but the Inoue method had a screening time of 21 minutes compared with the 40 minutes of the double balloon method. The cost of disposable equipment was $40 \%$ higher with the Inoue method. In patients with a mean age of 56 , Kasper et al ${ }^{20}$ noted that in 22 patients treated by double cylindrical balloon, the haemodynamic result was not significantly better than in the 23 patients treated with the Inoue balloon: the pattern of complications was similar to that seen in our patients. In a further non-randomised comparison, Ruiz et $a l^{21}$ reported that, in patients with a mean age of 46 years, the double balloon method gave a significantly better haemodynamic improvement. The ratio of balloon diameter to mitral annulus diameter was much higher when they used double balloons, however. Even in a randomised trial, outcome could be influenced by the choices involved in the performance of the techniques. In a small randomised comparison in 16 patients selected for the absence of marked degenerative valvular change, Ribeiro et $a l^{22}$ found no significant difference in final valve area, although the procedure time of 140 (41) minutes with the Inoue balloon was shorter than the 220 (30) minute procedure time with the double balloon method. A similar conclusion was reached in the preliminary report of a larger (100 patients) randomised study from Korea. ${ }^{23}$

The design of the two types of balloon was also reflected in the complications experienced. Haemopericardium occurred only with the cylindrical balloons and was due to perforation of the left ventricular apex in two patients. The sharp hard tip of the cylindrical balloons was not able to be fully protected by a guide wire. Atrial septal defects were more common and larger with the cylindrical balloons, which did not regain their low profile shape on deflation. An increase in mitral reflux was seen more often with the Inoue balloon, however. The Inoue balloon is not ejected from a resistant orifice and may thereby create reflux by overdilatation at a commissure or by cusp tear. We had initially used the Inoue balloon to a diameter judged on total body size. Six patients were dilated to $32 \mathrm{~mm}$. By using the recommendation to restrict maximum balloon size according to patient height, ${ }^{24}$ the incidence of increased mitral reflux has been less. Three of our 70 patients treated by the Inoue balloon developed acute localised myocardial impairment typical of myocardial infarction. In one patient, this appeared due to a fragment from a split commissure. In a second patient, no evidence of embolism or thrombosis was found at necropsy. A third patient was noted to have developed inferior surface changes on later review of the angiogram: coronary angiography had not been repeated. On inflation, the Inoue balloon releases microbubbles of air from between the rubber walls and this may have resulted in coronary air embolism. We now repeatedly inflate the Inoue balloon under water before insertion.

We found the Inoue balloon was more effective for mitral valvotomy as it gave a shorter procedure time with less radiation exposure, had a reduced risk of major complications, and provided a greater control of the dilatation process.

The Inoue balloon equipment is expensive, costing $£ 1390$ ( $+17 \cdot 5 \%$ VAT) in the United Kingdom, but surgical treatment involves a much longer hospital stay than the 48 hours for percutaneous balloon valvotomy. In developing countries, where rheumatic fever is still common, use of medical resources has to be frugal. In these circumstances, balloon equipment would have to be resterilised for balloon valvotomy to be economically competitive with closed surgical valvotomy, even if percutaneous balloon valvotomy was performed on a day case basis. At present, neither type of balloon is ideal for developing countries. The Inoue balloon has a small hole in its outer rubber layer which allows blood to enter between the inner and outer walls, thus 
making resterilisation more difficult, whereas cylindrical balloons would require further modification to increase the ease and safety of their use.

1 Lock JE, Khalilullah M, Shrivastava S, Bahl V, Keane JF. Percutaneous catheter commissurotomy in rheumatic Percutaneous catheter commissurotomy in rhe

2 Al Zaibag M, Ribeiro PA, Al Kasab S, Al Fagih MR. Percutaneous double-balloon mitral valvotomy for rheumetic mital valve stenosis Lancet 1986;i:757-61.

3 Patel J, Vythimlgum S, Mithra AS. Balloon dilatation of the mitral valve by a single bifoil $(2 \times 19 \mathrm{~mm})$ or trefoil $(3 \times 15 \mathrm{~mm})$ catheter. Br Heart $\mathcal{f}$ 1990;64:342-6.

4 Babic UU, Dorros G, Pejcic P, et al. Percutaneous mitral valvuloplasty: retrograde, transarterial double-balloon technique utilising the transseptal approach. Cathet Cardiovasc Diagn 1988;14:228-37.

5 Stephandis C, Stratos C, Pitsavos C, et al. Retrograde nontransseptal balloon mitral valvuloplasty: immediate results and long-term followup. Circulation 1992:85: results 7 .

6 Palacios I, Block PC, Brandi S, et al. Percutaneous balloon valvotomy for patients with severe mitral stenosis. Circulation 1987;75:778-84.

7 Vahanian A, Michel PL, Cormier B, et al. Immediate and mid-term results of percutaneous mitral commissurotomy. Eur Heart f 1991;12(suppl B):84-9.

8 Ruiz CE, Allen JW, Lau FYK. Percutaneous double balloon valvotomy for severe mitral stenosis. $\mathrm{Am} \mathcal{f}$ Cardiol 1990;65:473-7.

9 Le fevre T, Bonan R, Serra A, et al. Resultats immediats et suivi a moyen terme apres valvuloplastie mitral percutanée. Arch Mal Coeur 1991;84:1311-9.

10 Inoue $\mathrm{K}$, Owaki $\mathrm{T}$, Nakamura $\mathrm{T}$, Kitamura $\mathrm{F}$, Miyamoto $\mathrm{N}$. Clinical application of transvenous mitral commissurotomy by a new balloon catheter. $\mathcal{F}$ Thorac Cardiovasc Surotomy by a new ball

11 Inour K. Percutaneous transvenous mitral commissurotomy using the Inoue balloon. Eur Heart $f$ 1991; 12(suppl B):99-108.
12 Hall RJC, Julian DG. Diseases of the cardiac valves. Eding Julian DG. Diseases of the

13 Cohen MV, Gorlin R. Modified orifice equation for the calculation of mitral valve area. Am Heart $\mathcal{F} 1972 ; 84$ : 839.

14 Carabello BA, Grossman W. Calculation of stenotic valve orifice area. In: Grossman $W$ and Baim DS, eds. Cardiac catheterisation, angiography and intervention. Philadelphia: Lea and Febiger, 1991:152-65.

15 Shaw TRD, Elder AT, Flapan AD, Essop AR. Mitral valvuloplasty for patients aged over 70 years: an alternative to surgical treatment. Age Ageing 1991;20:299-303.

$16 \mathrm{La}$ fevre $\mathrm{T}$, Bonan R, Serra A, Cretlan J, Dyrda I, Tetitclerc R. Percutaneous mitral valvuloplasty in surgi-
cal high risk patients. $\mathcal{F} \mathrm{Am}$ Coll Cardiol 1991;17: 348-54.

17 Shaw TRD, McAreavey D, Essop AR, Flapan AD, Elder AT. Percutaneous balloon dilatation of the mitral valve in patients who were unsuitable for surgical treatment. Br Heart f 1992;67:454-9.

18 Chen CR, Huang ZD, Lo ZX, Cheng TO. Comparison of single rubber-nylon balloon and double polyethylene balloon valvuloplasty in 94 patients with rheumatic mitral stenosis. Am Heart $\mathcal{f} 1990 ; 119: 102-11$.

19 Abdullah M, Halim M, Rajendran V, Sawyer W, al Zaibag $M$. Comparison of single (Inoue) and double balloon valvuloplasty: immediate and short term results. $A m$ Heart f 1992;123:1581-8.

20 Kasper W, Wollschlager H, Geibel A, Meinertz T, Just H. Percutaneous mitral balloon valvotomy-a comparative evaluation of two transatrial techniques. Am Heart $f$ 1992;124:1562-6.

21 Ruiz CE, Zhang HP, Macaya C, Aleman EH, Allen NW, Lan FYK. Comparison of Inoue single-balloon versus double-balloon technique for percutaneous mitral valvotomy. Am Heart f 1992;123:942-7.

22 Ribeiro PA, Fawzy ME, Arafat MA, et al. Comparison of mitral valve area results of balloon mitral valvotomy using Inoue and double balloon techniques. $A m \mathcal{F}$ Cardiol 1991;68:687-8.

23 Kim JJ, Park SJ, Park SW, Song JK, Lee SJK. Immediate and late results of percutaneous mitral balloon valvuloplasty using Inoue and double balloon methods: 1 year follow up. $7 \mathrm{Am}$ Coll Cardiol 1992;19:143A

24 Inoue $\mathrm{K}$, Hung J, Chen $\mathrm{C}$, Cheng TO. Mitral stenosis: Inoue balloon catheter technique. In: Cheng TO ed. Inoue balloon catheter technique. In: Cheng TO ed. Shoin, 1992:237-79. 